International Conference on Research in Education, Teaching and Learning

Paris, France| November 2 -4, 2018

\title{
Music Education as the Backbone of the Curriculum in Primary School
}

\author{
Ana-Mercedes Vernia-Carrasco \\ Jaume I University
}

\begin{abstract}
Music education as the backbone of the curriculum in primary education. Analyzed the curricula of primary education in the Valencia Community, we realize that music education connects with all subjects and matters, therefore, we propose an experimental proposal that connects the contents, fundamentals and competences of education and musical training, with the key competences. On the other hand, we consider music education as a tool that, in addition to facilitating learning, affects important parameters such as emotions and values, allowing interdisciplinarity and transdisciplinarity. However, in the European framework the basic competences, have been defined, applicable to all training, without taking into account the specificities of the curricular areas or subjects, as well as the special teachings, among which is Music. That is why it is necessary to define the key or basic competences in Music that must be related to the basic competences in order to have a greater significance and quality in education, attending to the diversity of training and employability.
\end{abstract}

Keywords: Primary School, Music Education, Key Competences Curriculum. Themes: Education Theory and Practice 
